\title{
Separation and Mapping of Chromosomes of Parasitic Protozoa
}

\author{
Rosaura Hernandez-Rivas, Artur Scherf ${ }^{+}$ \\ Unité de Parasitologie Expérimentale, CNRS URA 1960, Institut Pasteur, 25 Rue du Docteur Roux, 75724 \\ Paris Cedex 15, France
}

Many protozoan parasites represent an important group of human pathogens. Pulsed Field Gradient Gel Electrophoresis (PFGE) analysis has been an important tool for fundamental genetic studies of parasites like Trypanosoma, Leishmania, Giardia or the human malaria parasite Plasmodium falciparum. We present PFGE conditions allowing a high resolution separation of chromosomes ranging from 500 to $4000 \mathrm{~kb}$ within a two day electrophoresis run. In addition, we present conditions for separating large chromosomes (2000-6000 kb) within $36 \mathrm{hr}$. We demontrate that the application of two dimentional PFGE (2D-PFGE) technique to parasite karyotypes is a very useful method for the analysis of dispersed gene families and comparative studies of the intrachomosomal genome organization.

Key words: Pulsed Field Gradient Gel Electrophoresis - two dimensional PFGE - protozoan karyotypes chromosome mapping - dispersed gene families

In 1984, Schwartz and Cantor introduced a new technique in which periodic changing of the direction of the electric field at fixed time intervals allowed the separation of large DNA molecules $(>50$ $\mathrm{kb}$ ), called Pulsed Field Gradient Gel Electrophoresis (PFGE). Since then, various improvements of the PFGE technique have been made allowing for the separation of DNA molecules up to $13 \mathrm{Mb}$ in agarose gels (for review Lognonne 1993).

Protozoa have relatively small genomes ranging generally from several kilo base pairs to several mega base pairs. Classical genetic studies have been hampered by the absence of chromosome condensation during metaphase. Thus, PFGE analysis has been a very important tool for fundamental genetic studies of protozoan parasites such as Trypanosoma (Van der Ploeg et al. 1984), Leishmania (Giannini et al. 1986), Giardia (Adam et al. 1988) or the human malaria parasite Plasmodium falciparum (for review see Foote \& Kemp 1989). PFGE applications are successful in resolving karyotypes, demonstrating chromosome polymorphism and mapping of chromosomes of many

\footnotetext{
This work has been supported by a grant from Groupement de Recherches et d'Etudes sur les Genomes (GIP-GREG). R H-R was financed by fellowships from 'Pasteur-Weizmann' and 'Fondation pour la Recherche Médicale'.

${ }^{+}$Corresponding author. Fax:+33-1-4061.3185. E-mail ascherf@pasteur.fr

Received 20 August 1997

Accepted 10 September 1997
}

pathogens. Most protozoan parasites have chromosome sizes that can readily separated by PFGE. However, due to the complexity of many parasite karyotypes, the separation of chromosomes by PFGE of many of these pathogenic unicellular parasites can take prolonged electrophoresis time. For example, the time to separate the 14 chromosomes of $P$. falciparum has been reported to be one week (Dolan et al. 1993).

In this paper, we present protocols for the preparation, separation and digestion of agarose embedded intact high molecular weight DNA. We describe also recently improved PFGE conditions allowing high resolution separation of chromosomes of most parasitic protozoa within a two day electrophoresis run (Hinterberg \& Scherf 1994).

\section{MATERIALS AND METHODS}

SeaKem GTG agarose (FMC BioProducts) for agarose gels concentrations $>0.6 \%$ and chromosomal grade agarose (Bio-Rad) for agarose gels $<0.6 \%$. Low-melting point agarose (FMC BioProducts) for embedding parasites in agarose blocks and preparative isolation of chromosomes.

Molecular weight size standards: $5 \mathrm{~kb}$ ladder (4.9-120 kb), lambda ladder (0.05-1 Mb), Saccharomyces cerevisiae $(0.2-2.2 \mathrm{Mb})$ and Hansenular wingei (1-3.1 Mb) (Bio-Rad).

Erythrocyte lysis buffer: $0.15 \%$ saponin (Sigma) in phophate buffered saline (PBS).

Cell lysis buffer (CLB): 0.5M EDTA pH 8.0, $0.01 \mathrm{M}$ Tris- $\mathrm{HCl}, 1 \%$ sodium lauryl sarcosinate (Sigma). Store at room temperature. Before cell lysis add $2 \mathrm{mg} / \mathrm{ml}$ of Proteinase $\mathrm{K}$ from a stock solution. 
Ethidium bromide: $10 \mathrm{mg} / \mathrm{ml}$ in water.

Nylon membrane: Hybond $\mathrm{N}^{+}$(Amersham) or BIOTRANS $^{(+)}(\mathrm{ICN})$. These membranes allow the rapid alkaline transfer of DNA and the physical characteristics make them specially useful for multiple hybridization cycles (usually 5-10 cycles).

Alkaline transfer buffer: $0.4 \mathrm{M} \mathrm{NaOH}$.

Prehybridization and hybridization buffer: $0.5 \mathrm{M} \mathrm{NaPO}_{4}, \mathrm{pH} 7.2,7 \%$ SDS, $1 \%$ BSA.

20xSSC: $3 \mathrm{M}$ sodium chloride, $0.3 \mathrm{M}$ sodium citrate.

Saturated sec-butanol: mix sec-butanol with $1 \mathrm{M}$ $\mathrm{NaCl}$ in TE $(4: 1 \mathrm{v} / \mathrm{v})$. Add $9 \mathrm{vol}$ saturated sec-butanol and $1 \mathrm{vol}$ of the aqueous phase to the gel blocks. This is important to avoid gel shrinking!

10xTBE buffer: $108 \mathrm{~g}$ Tris base, $54 \mathrm{~g}$ boric acid, $8.35 \mathrm{~g}$ disodium EDTA per liter (pH approx. 8.5). 8.0.

TE buffer: $10 \mathrm{mM}$ Tris-HCl, $1 \mathrm{mM}$ EDTA $\mathrm{pH}$

Random prime labeling kit (Boehringer Mannheim or Amersham).

alpha- ${ }^{32} \mathrm{P}-\mathrm{dATP},>3000 \mathrm{Ci} / \mathrm{mmol}$.

Preparation of DNA for PFGE - The ability to preserve the intact size of large DNA molecules is critical for the success of PFGE. Very high molecular weight DNA samples are impossible to prepare by conventional solution methods because they are extremely sensitive to shear damage. To overcome this problem, intact cells are embedded in low melting agarose blocks (Schwartz \& Cantor 1984). Cells are lysed and proteins are removed by Proteinase $\mathrm{K}$ treatment. This procedure yields DNA that is both intact and susceptible to restriction enzyme digestion. The agarose block can be loaded directly into the well of a pulsed-field gel.

The host cell of the intracellular bloodstage form of $P$. falciparum needs to be lysed by saponin before embedding the parasite cells into agarose blocks. The first step of the protocol concerns only the preparation of chromosomes of plasmodial bloodstage parasites. If you work with free living parasites start with step 2 .
1. Estimate the volume of the erythrocyte pellet and add 1.5 vol of $0.15 \%$ saponin in PBS at room temperature. Resuspend the pellet and incubate for 3-5 min. The liquid will clarify as the red blood cells lyse. Add 5 vol of cold PBS and centrifuge at $5000 \mathrm{rpm}$ for $10 \mathrm{~min}$. Resuspend the dark pellet which contains the parasite material in $2 \mathrm{ml}$ PBS. 2 . Pellet the cells by centrifugation at $3000 \mathrm{rpm}$ for $10 \mathrm{~min}$ and resuspend at a concentration of approx. $5 \times 10^{8}$ parasites $/ \mathrm{ml}$ PBS.

3. Equilibrate the cell suspension at $37^{\circ} \mathrm{C}$ and add an equal volume of $1.6 \%$ melted low-melting point agarose $\left(37^{\circ} \mathrm{C}\right)$. Mix gently and dispense the cell suspension immediately into plastic gel molds (2x5x10mm, $100 \mathrm{ml}$ vol) (Pharmacia) and allow to solidify at $4^{\circ} \mathrm{C}$ for about $20 \mathrm{~min}$.

4. Place up to 20 solidified blocks in a volume of $10 \mathrm{ml}$ containing cell-lysis buffer (CLB) and incubate for $24 \mathrm{hr}$ at $42^{\circ} \mathrm{C}$. Replace the CLB with an equal volume of fresh CLB and incubate for additional $24 \mathrm{hr}$.

5. The blocks can be stored indefinitely in TE buffer at $4{ }^{\circ} \mathrm{C}$.

Electrophoresis conditions - Optimal separation of the different chromosome size classes usually requires the use of a range of different PFGE conditions. Table shows the running conditions of large DNA fragments of various sizes using the CHEF system. Several parameters that influence the DNA mobility, such as the temperature, the voltage, pulse time and agarose type have been modified to enhance the mobility of the chromosomes. The use of lower agarose percentages, higher output voltage in combination with one or two phase ramping switch time protocols reduced significantly the time of separation of chromosomes ranging from about 600 to $3500 \mathrm{~kb}$. A summary of run conditions for various size ranges are given in Table. The presented PFGE methods have been used in studies of $P$. falciparum and $T$. cruzi but also apply to other parasitic protozoa. The described electrophoresis conditions have been de-

TABLE

Electrophoresis conditions for separation of DNA fragments by PFGE (CHEF system)

\begin{tabular}{|c|c|c|c|c|c|}
\hline $\begin{array}{l}\text { Efficient } \\
\text { separation }\end{array}$ & $\begin{array}{l}\text { Pulse time } \\
\text { (ramping) }\end{array}$ & Voltage & Run time & $\begin{array}{l}\text { Agarose } \\
\text { concentration }\end{array}$ & Buffer \\
\hline $5-100 \mathrm{~kb}$ & $0.5 \mathrm{~s}-1.0 \mathrm{~s}$ & $400 \mathrm{~V}$ & $7 \mathrm{hr}$ & $1.3 \%$ & $0.2 \times \mathrm{TBE}$ \\
\hline $50-2000 \mathrm{~kb}$ & $50 s-90 s$ & $200 \mathrm{~V}$ & $22 \mathrm{hr}$ & $1.0 \%$ & $0.5 \times \mathrm{TBE}$ \\
\hline $500-4000 \mathrm{~kb}$ & $90 \mathrm{~s}-300 \mathrm{~s}$ for $24 \mathrm{hr}$ & $95 \mathrm{~V}$ & & & \\
\hline & $\begin{array}{l}\text { followed by } \\
300 \mathrm{~s}-720 \mathrm{~s} \text { for } 24 \mathrm{hr}\end{array}$ & $85 \mathrm{~V}$ & $48 \mathrm{hr}$ & $0.7-0.8 \%$ & $0.5 \times \mathrm{TBE}$ \\
\hline $2000-6000 \mathrm{~kb}$ & $120 s-720 s$ & $85 \mathrm{~V}$ & $36 \mathrm{hr}$ & $\begin{array}{l}0.4-0.6 \% \\
\text { (high gel strength } \\
\text { agarose) }\end{array}$ & $0.5 \times \mathrm{TBE}$ \\
\hline
\end{tabular}


veloped for the Pulsaphor/Gene Navigator PFGE apparatus (Pharmacia) based on the CHEF (clamped homogeneous electric field) design. Similar results have been obtained with the CHEF-DR system (Bio-Rad).

1.The agarose concentration and type of agarose depends on the DNA size range to be separated. For example, pulsed field separations larger than 2 megabases are improved by using high gel strength agarose (Chromosomal grade agarose, Bio-Rad) allowing preparations of very low percentage agarose gels $(0.4-0.6 \%)$.

2. For a $15 \mathrm{~cm} \times 15 \mathrm{~cm} \times 0.5 \mathrm{~cm} 1 \%$ agarose gel, dissolve $1.1 \mathrm{~g}$ SeaKem GTG agarose in $110 \mathrm{ml} 0.5$ $x$ TBE buffer by heating in a microwave oven. Make sure that the volume has not changed. Otherwise adjust again to $110 \mathrm{ml}$.

3. Cool the agarose in a $50^{\circ} \mathrm{C}$ waterbath and pour into the casting stand.

4. After the gel is solidified, fill the wells with 0.5 $x$ TBE buffer and insert the blocks containing parasite DNA. About 2-5 mm of a block (1-2.5 $\times 10^{7}$ parasites) generally contains enough material to visualize the chromosomes of many protozoan parasites (Plasmodium, Leishmania and Trypanosoma) after ethidium bromide staining. However, for best PFGE results it might be necessary to determine for each organism the optimal number of cells /block.

5. Seal the blocks into the well with $1 \%$ low melting point agarose.

6. Fill 2.21 of TBE buffer in the electrophoresis chamber. The buffer should just cover the top of the agarose gel. The temperature of the running buffer $\left(18^{\circ} \mathrm{C}\right)$ is generally kept constant during the run.

7. The running conditions which allow the separation of plasmodial and most other protozoan parasite chromosomes in one run $(500-4000 \mathrm{~kb})$ are shown in Table.

Staining of chromosomes and southern hybridization - 1. After the completion of the run chromosomes can be visualized by staining the agarose gel for $15 \mathrm{~min}$ in ethidium bromide $(1 \mathrm{mg} / \mathrm{ml}$ $\mathrm{H}_{2} \mathrm{O}$ ). The gel is destained by two washes in $0.5 \times$ TBE for $1 \mathrm{hr}$ with gentle agitation and photographed (do not forget the ruler) using a shortwave UV-light $(254 \mathrm{~nm})$. If chromosomes are intended to be used for subsequent restriction mapping studies longwave UV-light ( $360 \mathrm{~nm}$ ) has to be used to avoid nicking of the DNA.

2. For Southern hybridization the DNA is transfered from the agarose gel to a nylon membrane such as Hybond $\mathrm{N}^{+}$or BIOTRANS ${ }^{+}$. In order to ensure efficient transfer of large DNA fragments the chromosomal DNA has to be nicked. This can be achieved by exposing the stained aga- rose gel for $5 \mathrm{~min}$ on a UV-light table $(254 \mathrm{~nm})$. 3 . The alkaline transfer procedure using $0.4 \mathrm{~N}$ $\mathrm{NaOH}$ as transfer buffer works fine for chromosome DNA blots. We routinely set up the capillary transfer (standard molecular biology procedure) for at least $24 \mathrm{hr}$. Make sure that the weight on top of the absorbent paper stack does not exceed 0.5-1 $\mathrm{kg}$. There is no need to fix DNA after alkali blotting.

4. ${ }^{32} \mathrm{P}$-labeld DNA probes using the random hexamer priming method in combination with the hybridization buffer 7\% SDS, 0.5 M EDTA pH 8.0, $1 \% \mathrm{BSA}$, gives usually a good signal to background ratio with nylon membranes. Single copy genes of $P$. falciparum are generally detected after $6 \mathrm{hr}$ to overnight exposure.

5. Probes are removed by standard protocols or as recommended by the manufacturer and stripped blots can be stored for prolonged periods at room temperature.

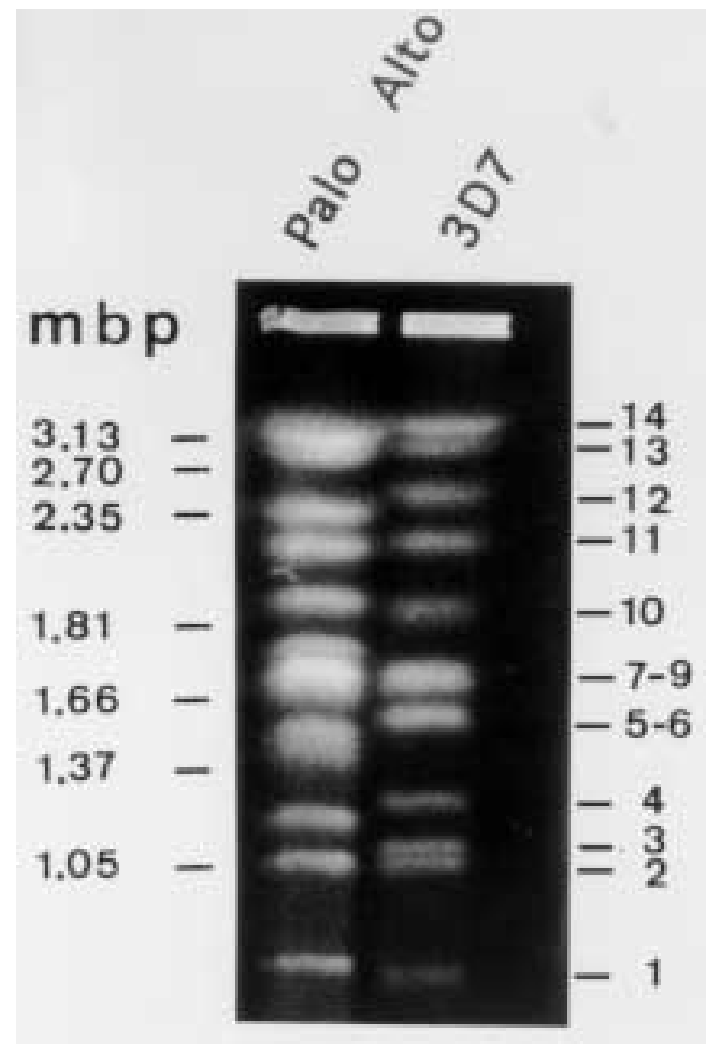

Fig. 1: fractionation of Plasmodium falciparum chromosomes by PFGE. The chromosomes were from clone 3D7 and the line Palo Alto and the chromosome size marker from yeast (Hansenula wingei, BioRad). Approx. $2 \times 10^{7}$ parasites were applied per lane. DNA separation was performed on a CHEF apparatus (BioRad) using a $0.8 \%$ agarose gel in $0.5 \mathrm{x}$ TBE at $18^{\circ} \mathrm{C}$. Switch time was ramped from $90 \mathrm{sec}$ to $300 \mathrm{sec}$ for $24 \mathrm{hr}$ at 95 volts followed by switch time ramped from $300 \mathrm{sec}$ to 720 sec for $24 \mathrm{hr}$ at 85 volts. 
Restriction enzyme digestion of embedded chromossomes - Generally, restriction enzymes diffuse into agarose blocks and thus, are suited for chromosome mapping studies. The most useful restriction endonucleases are those with eight base recognition sites which cut only a few times in chromosome sized DNA fragments. However, in genomes which are biased in their AT content, such as $P$. falciparum, certain enzymes which recognize GC-rich six base pair sequences (SmaI, BglI) can also be used as 'rare' cutters in these AT-rich genomes.

1. For restriction enzyme digestion of agarose embedded total parasite DNA, lysis buffer has to be removed by extensive washes in TE buffer (2-3 washes in $20 \mathrm{ml} \mathrm{TE}$ ). Any remaining proteinase $\mathrm{K}$ has to be inactivated by treating the blocks with 1 $\mathrm{mM}$ phenylmethylsulphonyl fluoride (PMSF) in TE (10 $\mathrm{ml}$ for 20 blocks) for $2 \mathrm{hr}$ at room temperature followed by three washes in $10 \mathrm{ml} \mathrm{TE}$ for 30 min each.

2. Individual chromosomes or DNA fragments that have been cut out from a stained agarose gel after a PFGE run must be treated with sec-butanol to extract remaining ethidium bromide prior restriction enzyme digestion. Add 9 vol of sec-butanol saturated in $1 \mathrm{M} \mathrm{NaCl} / \mathrm{TE}$ and $1 \mathrm{vol}$ of the aqueous phase to the gel block $(5: 1, \mathrm{v} / \mathrm{v})$ and agitate at room temperature for $30 \mathrm{~min}$. Repeat twice the extraction and wash the block five times in $10 \mathrm{ml}$ TE buffer for $30 \mathrm{~min}$ each. Store blocks at $4^{\circ} \mathrm{C}$.

3 . Equilibrate the blocks with $5 \mathrm{vol}$ of restriction buffer containing $100 \mathrm{mg} / \mathrm{ml}$ nuclease free BSA for $30-60 \mathrm{~min}$ at room temperature. Remove the buffer and add 2 vol of fresh buffer and the restriction endonuclease (approx. 100-200U/ml). Incubate at the recommended temperature for $4 \mathrm{hr}$ or over night.

4. Partial digestion of chromosome DNA is useful for mapping studies. In this case separate digestions of serial dilution of the restriction enzyme $(0.01 \mathrm{U} / \mathrm{ml}, 0.1 \mathrm{U} / \mathrm{ml}, 1 \mathrm{U} / \mathrm{ml}, 10 \mathrm{U} / \mathrm{ml}$ and $100 \mathrm{U} / \mathrm{ml})$ can be performed for $2 \mathrm{hr}$. Reactions will be stopped by adding EDTA to a final concentration of $50 \mathrm{mM}$.

5. Depending on the expected fragment size, re-

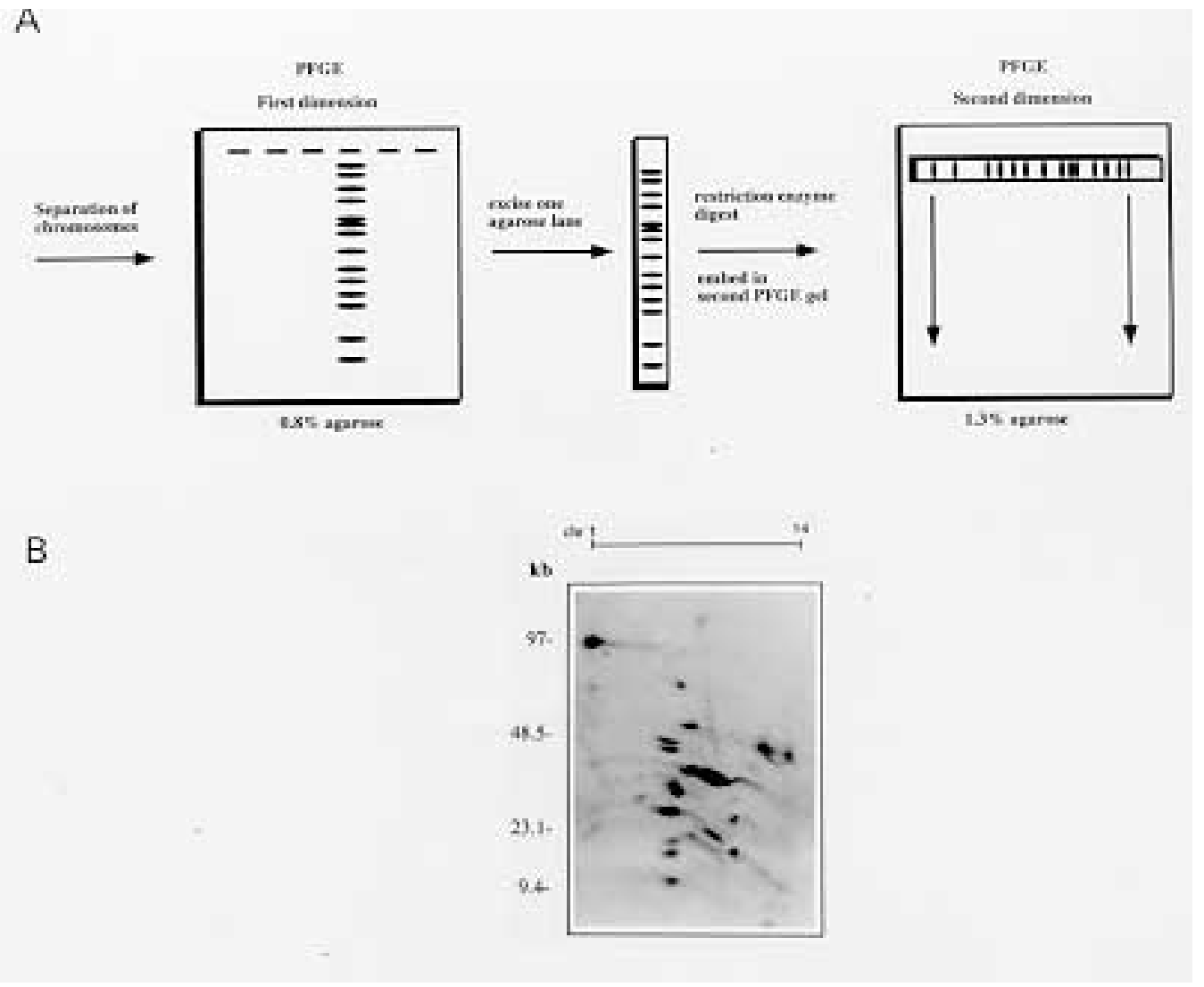

Fig. 2: two dimensional PFGE. A: schematic representation of 2D-PFGE B: Southern-blot of 2D-PFGE analysis of Plasmodium falciparum chromosomes digested with EcoRI. A DNA probe was used that hybridizes to a large gene family dispersed on various chromosomes. The chromosome number is indicated in the top of the gel. 
stricted DNA will be separated by PFGE according to the run conditions described in Table.

Two dimensional PFGE - Most chromosomes of a given protozoan parasite are heterogeneous in size and thus can be separated from each other by PFGE. Two dimensional (2D)-PFGE studies of a karyotype can give useful information concerning genetic markers located on several chromosomes. Multi-gene families are often observed in pathogenic protozoa. A schematic view of a 2D-PFGE is shown in Fig. 2A. An example of a 2D-chromosome blot of P. falciparum is shown in Fig. 2B.

1. Chromosomes are separated in the first dimension and stained with ethidium bromide as described above.

2. The gel is photographed using longwave UVlight $(360 \mathrm{~nm})$ and strips of gel (approx. $2 \mathrm{~mm}$ ) containing all chromosomes are excised with a razor blade. Ethidium bromide is extracted using secbutanol in a $15 \mathrm{ml}$ Falcon tube.

3. Restriction enzyme digestion is performed as described.

4. The slice of gel containing the digested chromosomes and size markers (lambda ladder or $5 \mathrm{~kb}$ ladder) is embedded into a precut slot in the top of a $1.3 \%$ agarose gel and sealed with $1 \%$ low melting point agarose.

5. Carry out standard PFGE separation using the run conditions described in Table. For Southern hybridization continue as described previously.

\section{ACKNOWLEDGEMENTS}

To Prof. L Pereira da Silva for his support.

\section{REFERENCES}

Adam RD, Nash TE, Wellems TE 1988. The Giardia lamblia trophozoite contains sets of closely related chromosomes. Nucl Acids Res 16: 4555-4567.

Dolan SA, Adam RD, Wellems TE 1993. Chromosome mapping methods for parasitic protozoa. In Methods in Molecular Biology: Protocols in Molecular Parasitology, NJ Human Press Inc., Totawa.

Foote S, Kemp DJ 1989. Chromosomes of malaria parasites. Trends Genet 5: 337-342.

Giannini SH, Schittini M, Keithly JS, Warburton PW, Cantor CR, Van der Ploeg LH 1986. Karyotype analysis of Leishmania species and its use in classification and clinical diagnosis. Science 232: 762765.

Hinterberg K, Scherf A 1994. PFGE: Improved conditions for rapid and high-resolution separation of Plasmodium falciparum chromosomes. Parasitol Today 10: 225 .

Lognonne JL 1993. Methods in Mol Cell Biol 4: 49-55.

Schwartz DC, Cantor CR 1984. Separation of yeast chromosome-sized DNAs by pulsed field gradient electrophoresis. Cell 37: 67-75.

Van der Ploeg LH, Schwartz DC, Cantor CR, Borst P 1984. Antigenic variation in Trypanosoma brucei analyzed by electrophoretic separation of chromosome-sized DNA molecules. Cell 37: 77-84. 
